\title{
ICAM'97/E-MRS'97 Spring Meeting Addressed Topics from Basic to Applied Research
}

More than 1,000 materials scientists, engineers, physicists, and chemists from 64 countries worldwide attended the International Conference on Advanced Materials and European Materials Research Society Spring Meeting (ICAM/ E-MRS'97 Conference) at the Palais de Congrès, Strasbourg, France, June 16-20, 1997. Thirteen symposia with 1,230 oral and poster presentations were devoted to high-tech materials and processes. The conference program offered a range of topics from fundamental research to applied research with medium and shortterm perspectives.

E-MRS addressed present-day demands in the selection of the symposia topics. The subjects included computational modeling issues in materials science, epitaxial thin film growth, characterization, surface science, III-nitrides, photonics, and biomaterials, including political questions at the interface of science, economy and policy, advanced materials education, and sustainable development in biodegradable polymers and macromolecules, environmentally-friendly energy sources, and the materials aspects of transportation.

The following descriptions of symposia are typical examples and give impressions of the ICAM'97/E-MRS'97 Conference: Symposium A on Fullerenes and CarbonBased Materials covered recent developments in more than 100 papers. One of the highlights was the contribution of 1996 Nobel Prize recipient H.W. Kroto of the University of Sussex, Brighton, United Kingdom, with new results on polymerized $\mathrm{C}_{60}$, single-wall nanotubes, and superhard and ultrahard materials, including supersmooth diamond films.

Symposium B on Epitaxial Film Growth and Nanostructures demonstrated the increasing effort of many research centers for epitaxy of thin layers and low-dimensional systems. However, not only the classical materials applied for low-dimensional systems (III-V semiconductors, $\mathrm{Si} / \mathrm{Si} / \mathrm{Ge}$ heterostructures) were studied, but epitaxial layers and nanoparticles and dots of metals and metal oxides as well, including $\mathrm{Co} / \mathrm{Cu}, \mathrm{Co} / \mathrm{Pd}, \mathrm{Fe} / \mathrm{Pd}, \mathrm{Fe} / \mathrm{Cu} / \mathrm{Au}$, $\mathrm{Pd} / \mathrm{Cr}, \mathrm{Au} / \mathrm{Ni}$, high-temperature superconductors such as $\mathrm{YBCO}$, tantalum oxide, and $\mathrm{FeO}$.

New epitaxial growth methods that were presented included atomic layer epitaxy (ALE) of SiGe and III-V semiconductors, low-energy plasma deposition (LPE) of $\mathrm{Si} / \mathrm{SiGe}$, laser-assisted molecular-beam epitaxy (MBE) techniques for II-V com- pounds, magnetron sputter epitaxy (MSE) of $\mathrm{Si}$, and ultrasound radiation methods for the preparation of nanometer-size particles. Successful methods creating nanoparticles and dots were the application of scanning tunneling microscopy (STM) metal tips, techniques of self-organized growth of nanoparticles and dots by sputtering, metalorganic chemical vapor deposition (MOCVD), and MBE. Interesting atomic scale characterization methods included high-resolution transmission electron microscopy (TEM) for microscopic diffusion phenomena, in situ ellipsometry for Al-CVD, surface wave propagation studies, and reflectance anisotropy spectroscopy for the characterization of lowdimensional systems. A new method for submicrometer patterning of silicide layers by local oxidation was also presented.

The largest symposium was D on Computational Modeling Issues in Materials Science, exemplifying the increasing importance attached to computational materials science. Parallel computers will play a major role in the further development of the field: Simulations with 100 million atoms approaching macroscopic dimensions have now become possible on the latest parallel hardware. Clearly, new algorithmic ideas will be needed and, in particular, scalable software will be essential for further progress. Thus, so-called order- $\mathrm{N}$ methods were the subject of lively debates.

Another clear trend is the emergence of the Car-Parinnello method as a work horse for the most advanced simulations, simultaneously combining electronic structure and molecular dynamics optimization. Only a few years ago it was considered computationally very expensive and of a sophistication that only experts could use it. The advent of faster hardware and the diffusion of computer codes have brought this technique within the reach of many research groups.

Atomistic simulations frequently operate on microscopic time and length scales: Nanometers and femtoseconds are the basic units in this realm. While a correct description of many observations requires quantum mechanics for a true understanding, the relevant measurements are done on a macroscale. How to consistently go from the micro- to macroscale (and also describe the intermediate mesoscale) remains one of the great unsolved puzzles in computational materials science and was the subject of much discussion at the symposium.

Symposium F on Advanced Materials
Education and Training pointed out the new ways and methods for education and training. Media network education is now starting in Europe. Databanks; new software such as fluent, batchcad, oracle, dynamic simulation, molecular modeling, and their applications through a European network; intelligent new materials; corrosion phenomena; and deposition of thin films or electronic materials seems to be key issues for education and training.

Symposium $\mathrm{H}$ on Biodegradable Polymers and Macromolecules covered all major aspects which are currently investigated in the field of biodegradable polymers. Various polymer classes such as polyamides, lignin, polyesters, polysaccharides, complex polymeric materials, and rubbers were covered, and aspects of biosynthesis, chemical synthesis, and biodegradation were presented. Other major aspects of this symposium were ecological considerations on the use, application, and production of biodegradable polymers as well as efforts to achieve standardized test methods to investigate and characterize the biodegradability in particular of technical relevant polymers. Economic considerations on the production of technically relevant polymers by the chemical industry, and the prospects for the production of such polymers by means of transgenic plants, were also presented and discussed.

This symposium covered a stimulating mixture of basic research and applied/ industrial research, and it brought together scientists with a range of backgrounds and affiliations from many countries worldwide. The relevance of the symposiumtopic was confirmed by the attendance of many representatives from the European chemical industry and major companies.

Symposium J on Light-Weight Materials for Transportation presented interdisciplinary information and created a discussion forum between materials scientists and transportation engineers. Papers came from the European car industry (e.g., BMW, Daimler Banz AG; Adam Opel AG, Renault or related companies), and, on the other hand, were given by materials scientists or by high-ranking managers of materials-producing companies. The symposium started with an overview of the materials in the new Roadster of Daimler Benz AG. Aluminum casting, magnesiumapplication, and fiber-reinforced plastic material in automotive application completed the picture of the advantages using light-weight materials for transportation. 
Special new automotive applications are Al-SiC composite brake discs and special composites for bearings and coatings. In the materials area, the papers covered aluminum foams, light-weight carbon fiber rods (which will be used in the next Zeppelin air ship), casting technology of aluminum and magnesium, and laserbeam welding of these materials, as well as research on the behavior of bubbles in welding for repairs in space. Welding, such as friction stir welding, was a special attraction to the audience, as in the connecting technology of new materials (e.g., welding, gluing). There are obvious needs for future development.
At Symposium $\mathrm{K}$ on Coatings and Surface Modifications for Surface Protection and Tribological Applications more than 120 papers indicated a very active scientific community and reflected the substantial progress and innovation in a wide range of basic processes and also of the industrial applications that are being made. Important technologies are plasma deposition of coatings on cold rolled steels for long-term corrosion protection, and electron beam physical deposition (EB-PVD) to produce thick adherent gradient coatings for thermal barriers or wear-resistant coatings for hightemperature applications. Many advances in magnetron sputtering technology are stimulated by industrial applications. New approaches using duplex combinations of processes and multilayered or multiphased coatings are very promising for producing coatings to resist specific wear phenomena. Another emerging technology for modification of mechanical surface properties is plasma immersion ion implantation which allows the ability to implant high doses of ions (mainly nitrogen) on all sides of the sample.

P. GLASOW
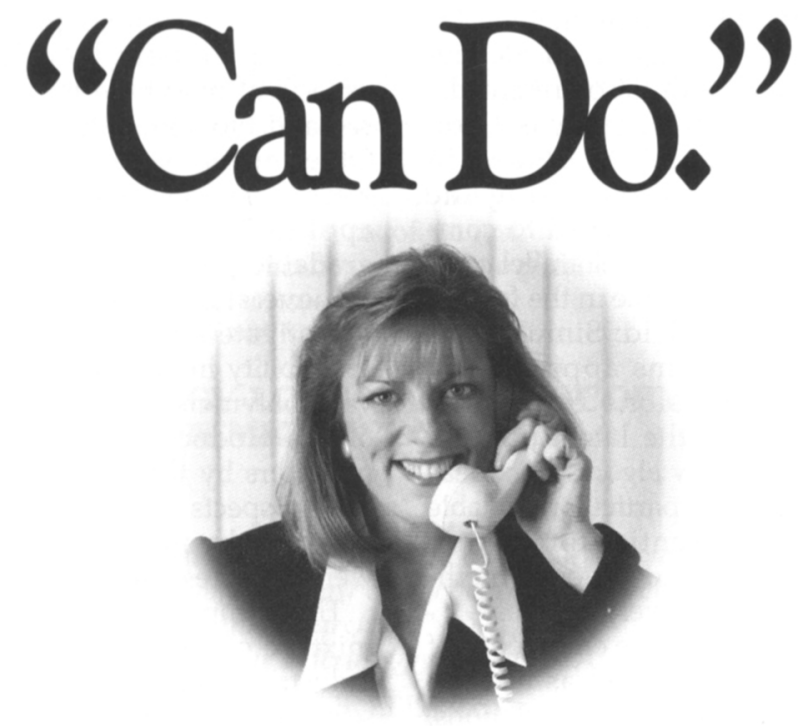

\section{Whatever You Need in Inorganics - We'll Work With You to Make It Happen. \\ "Yes." That's a word you'll hear a lot at Cerac. From the rarest inorganics to the most common, you'll find us ready, willing and able to provide exactly what you want. Right away. Without the burden of sourcing multiple vendors to get the job done. Why? Because we have what it takes - a "Can Do" attitude and the widest selection of inorganics in the business - produced right here at Cerac. So you know you're always \\ getting the highest quality and consistency. Need a small lab quantity? "Can do." Want precision scale-up fast? "Can do." Want to save money buying direct from the manufacturer? "Can do." Want to find out for yourself? Just pick up the phone and give us a call. \\ Ask For Our Free Catalog $414-289-9800$}

- Virtually Any Size or Shape: Powders, Evaporation Materials, Sputtering Targets

- Quantities from Grams to Thousands of Kilograms
- The World's Widest Selection of Inorganics

- Nearly Any Composition

- Custom Manufacturing

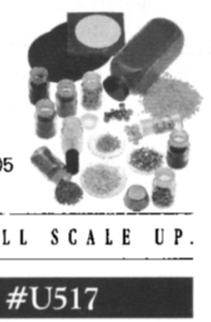

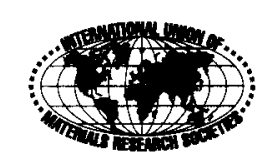

News About IUMRS Conferences and Other Activities Should Be Sent To:

MRS Bulletin

Materials Research Society 506 Keystone Drive

Warrendale, PA 15086-7573

USA

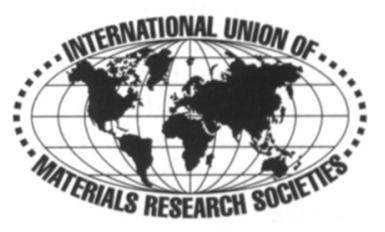

M|R|S

E-mail: bulletin@mrs.org 


\section{New and Bestselling Books from Springer}

Now the Publisher of AIP PRESS

J.T. YATES, JR., University of Pittsburgh, PA

EXPERIMENTAL INNOVATIONS IN SURFACE SCIENCE

A Guide to Practical Laboratory Methods and Instruments

EXPERIMENTAL

INNOVATIONS IN SURFACE SCIENCE

This source book of the "tricks of the trade" of surface science contains descriptions (with at least one facing illustration for each)of hundreds of techniques, methods, instruments, and tools in common use in surface science. The methods are arranged in topical groupings for easy reference. Each is described succinctly, with a clear sketch of the apparatus involved (and, in many cases, of the physical principles as well). Covers all the basic methods of surface science, and, thus, will serve not only as a useful reference to those just starting on experimental research in surface science, but also as a "vade mecum" for established researchers. 1997/APPROX. 920 PP.. 567 ILLUS./HARDCOVER/\$89.95 ISBN 0-387-98332-5

\section{R. E. HUMMEL, University of Florida, Gainesville, FL \\ UNDERSTANDING \\ MATERIALS SCIENCE \\ History, Properties, Applications}

This introduction to materials science for engineers examines not only the physical and engineering properties of materials, but also their history, uses, development, and some of the implications of resource depletion, materials substitutions, and so forth. Topics covered include: the stone, copper, bronze, and iron ages; physical properties of metals, ceramics, and plastics; electrical and magnetic properties of metals, semiconductors, and insulators; band structure of metals; and the metallurgy of iron. Complimentary examination copies available to qualified instructors.

1998/APPROX. 320 PP., 35I ILLUS.JHARDCOVER/\$59.95 ISBN 0-387-98303-I

P.Y. YU, University of Califomia, Berkeley, and M. CARDONA, MPI für Festkörperforschung,

Stuttgart, Germany

\section{FUNDAMENTALS OF \\ SEMICONDUCTORS}

\section{Physics and Materials Properties}

Provides a bridge between a graduate-level solidstațe physics textbook and research articles by offering detailed explanations of the electronic, vibrational, transport, and optical properties of semiconductors. Theories are presented to explain experimental results. Written with both students and researchers in mind, the emphasis is on understanding the physical properties of silicon and similar tetrahedrally coordinated semiconductors.

1996/617 PP. 246 ILLUS., 50 TABLES/SOFTCOVER/S49.95 ISBN 3-540-61461-3

S. NAKAMURA, Nichia Chemical Industires Ltd Takushima-Ken, and G. FASOL, Eurotechnology Jopon Ltd, Tokyo, both japan

\section{THE BLUE LASER DIODE}

\section{GaN Based Light Emitters and Lasers}

Written by the developer of this major advance in semiconductor lasers, Shuji Nakamura, this book summarizes the basic principles, operating characteristics, and expanding application of blue $\mathrm{GaN}$-based laser diodes. This first monograph on the subject examines the specifics of the technology and records the history of its development.

1997/343 PP., 246 ILLUS.., 49 TABLES/HARDCOVER/\$69.95 ISBN 3-540-61590-3

\section{R. C. POWELL, University of Arizona, Tucson \\ PHYSICS OF SOLID-STATE LASER MATERIALS}

This professional reference and graduate-level text presents the fundamental physics of solid-state lasers, including the basis of laser action and the optical and electronic properties of laser materials. The discussion is as self-contained as possible, making the book an excellent reference as well as useful tool for independent study. It covers all of the chief types of important solid-state laser materials, including their operating characteristics. Treats in greatest detail the subjects of specific solid-state laser materials, the prototypical ruby, and $\mathrm{Ng}$-YAG systems.

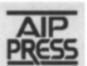

1998/APPROX. 372 PP., I35 ILLUS.

HARDCOVER/\$59.95/ISBN I-56396-658-

ATOMIC, MOLECULAR \& OPTICAL PHYYICS SERIES

T. ISHIGURO, Kyoto Universtiy, K. IBARAKI, and G.SATO, all, japan

\section{ORGANIC SUPERCONDUCTORS Second Edition}

Introduces organic conductors and superconductors and reviews the current status of the field. First organic conductors are described; then the structures and electronic properties of organic superconductors are discussed and illustrated with examples of typical compounds. The book deals in detail with theories of the mechanism of superconductivity, and more briefly with spin-density waves. This second edition covers the research activities of the last few years. I997/APPROX. 300 PP., 189 ILUUS./SOFTCOVER/\$54.00 (TENT.) ISBN 3-540-63025-2

SPRINGER SERIES IN SOLID-STATE SCIENCES, VOL 88

H. BACH and D. KRAUSE, both, Schott Glass Works, Germany (Ed.)

\section{THIN FILMS ON GLASS}

This monograph describes recent and previous results of the development of activities and passive thin films on glass at Schott. It reports on design strategies, the use of conventional and newly developed production technologies of thin films on glass. and the application of characterization methods for the structure of thin films and their properties. Several examples illustrate how the combined application of design strategies, deposition and characterization methods provides the basis for selecting the best suited film materials, deposition and processing parameters.

1997/APPROX. 416 PP., 169 ILLUS.JHARDCOVER/\$169.00 ISBN 3-540-58597-4

SCHOTT SERIES ON GLASS AND GLASS CERAMICS
New Edition -

R.Y. DONG, Brandon University, MB, Canada

\section{NUCLEAR MAGNETIC RESONANCE OF LIQUID CRYSTALS \\ Second Edition}

The book begins with a survey of liquid crystal phases and field effects and with an introduction to the basic physics of nuclear magnetic resonance; it then discusses orientational ordering and molecular field theories for various liquid crystal molecules and NMR studies of uniaxial and biaxial phases. This second edition is updated throughout. 1997/309 PP., 141 ILLUS./HARDCOVER/\$69.95 ISBN 0-387.98230-2

PARTIALLY ORDERED SYSTEMS

\section{V.V. SCHMIDT}

(P. MÜLLER and A. USTINOV, both, University of Erlangen, Germany (Eds.))

\section{THE PHYSICS OF SUPERCONDUCTORS}

Introduction to Fundamentals and Applications

This modem tutorial on the physics of superconductors covers key topics such as Ginzburg-Landau theory, Josephson effects, SQUIDS, and the macroscopic theory of Bardeen, Cooper, and Schrieffer. Written primarily as a graduate-level text and reference, the book contains numerous problems, accompanying solutions, and the most recent developments, such as high- $T_{c}$ superconductors |997/218 PP., III ILLUS./\$59.95/ISBN 3-540-61243-2

\section{FOUR EASY WAYS TO ORDER}

- CALL Toll Free: 800-SPRINGER 8:30 am-5:30 pm EST; or FAX 201-348-4505; Please mention Code $\$ 683$ when ordering by phone

- WRITE to Springer-Verlag New York, Inc., Dept 5683

PO Box 2485, Secaucus, NJ 07096-2485:

- E-MAIL orders@springer-ny.com

Outside North America, orders@springer.de:

- VISIT your local scientific bookstore or urge your libranian to order. Payment may be made by check, purchase order, or major credit card. Prices payable in U.S. dollars or the equivalent and subject to change without notice. Please include $\$ 3.00$ for shipping one book ( $\$ 1.00$ for each additional) \& appropriate sales tax if you reside in CA IL, MA, MO, NJ. NY, PA, TX, VA, or VT. Canadian residents. please add $7 \%$ GST. Remember...your 30-day return privilege is always guaranteed!

$$
11 / 97 \text { Ref. \#5683 }
$$

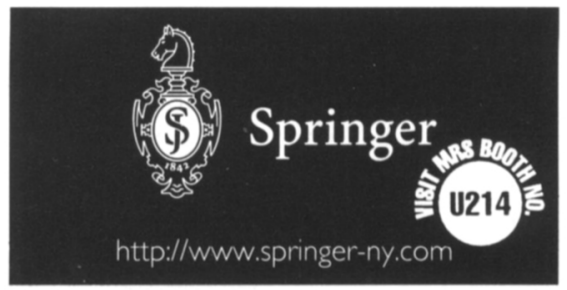




\section{For ISO 9000}

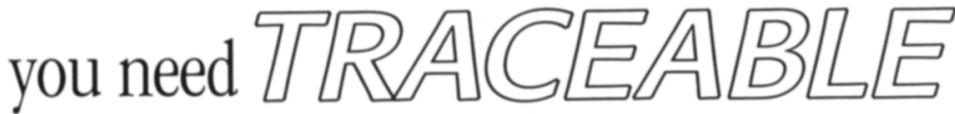

\section{CAIIBRA'TION standards}

for your METROLOGY. And

\section{here's the place to get them $y$}

Now, get traceable calibration standards and references for Surface Profiling, Film Thickness, Surface Contamination, Surface Characterization, Electrical, and Critical Dimension metrology, and more. Get the free catalog: VLSI Standards, 3087 N. $1^{\text {st }}$ St. San Jose, CA 95134. Phone: (408)428-1800. Fax: (408)428-9555. Web site: www.vlsistd.com

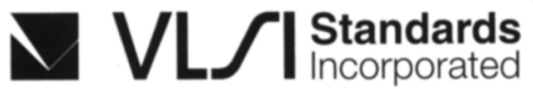

The Measurement Standards for the Industry

Circle No. 49 on Reader Service Card.

\section{8 ADVERTISING OPPORTUNITIES IN MRS BULLETIN}

\section{JANUARY}

Theme: Technical Features/Special Features

Advertising Closing: December 1, 1997

\section{FEBRUARY}

Theme: Quantum Dots

Guest Editor: Alex Zunger, National Renewable Energy Laboratory

Preview: 1997 MRS Spring Meeting \& Exhibit

Advertising Closing: January 2, 1998

\section{MARCH}

Theme: Materials for Sports

Guest Editor: F.H. Froes, University of Idaho

Bonus Distribution: 1998 MRS

Spring Meeting \& Exhibit;

Society of Vacuum Coaters (SVC) Conference

Advertising Closing: February 2, 1998

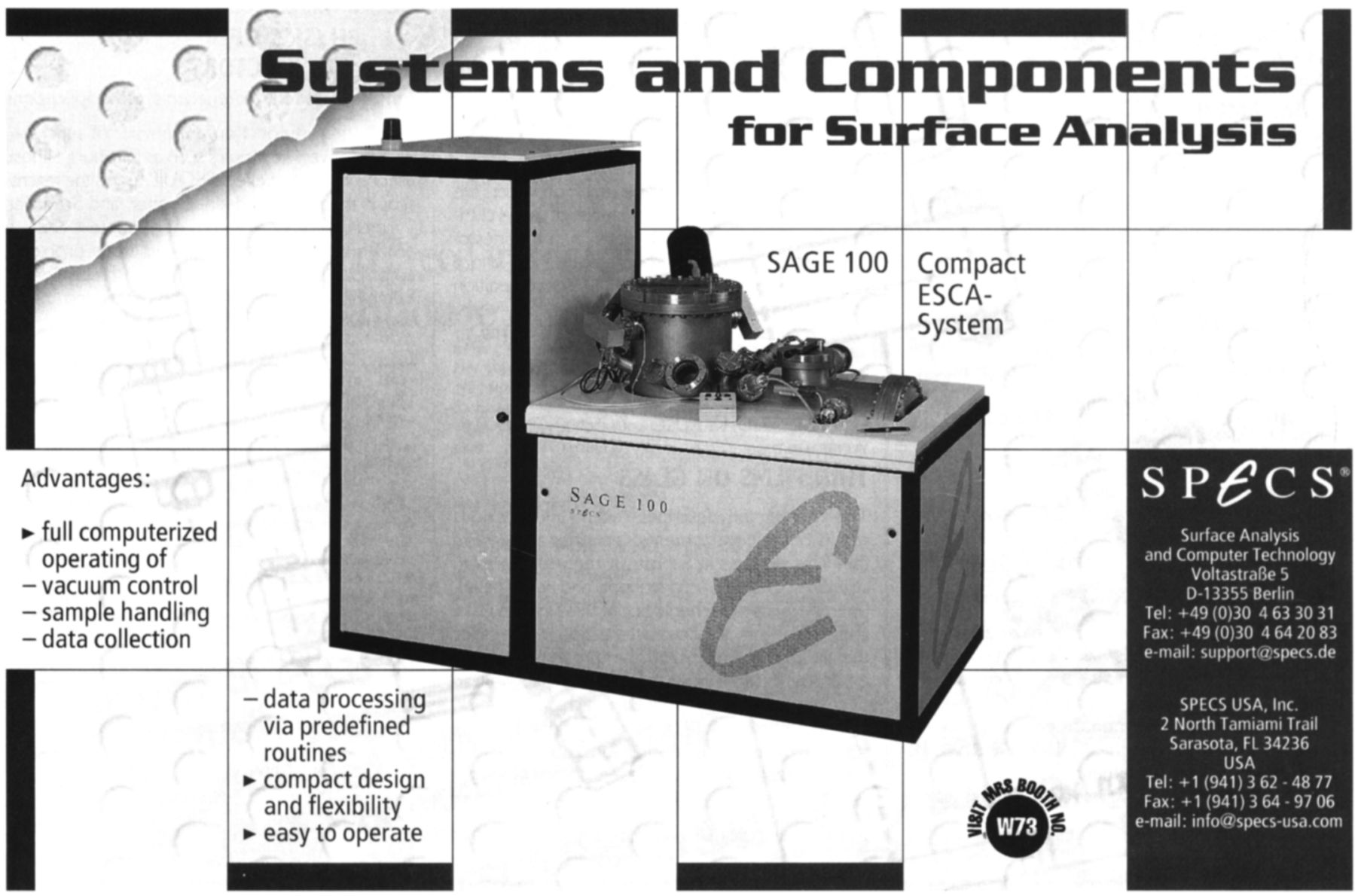

